8.

Teoría del Derecho 

Revista de Derecho

de la Pontificia Universidad Católica de Valparaíso

XXXII (Valparaíso, Chile, $1^{\text {er }}$ Semestre de 2009)

[pp. 533 - 557]

\title{
ALGUNAS CRÍTICAS A LA IDEA DE RAZÓN PÚBLICA RAWLSIANA
}

["Some of the Criticisms to Rawls' Idea of Public Reason"]

\author{
Luis Villavicencio Miranda* \\ Universidad de Valparaíso
}

RESUMEN

Este artículo analiza algunas críticas hechas a la idea de razón pública defendida por Rawls. Luego de explicar en la introducción la concepción rawlsiana de razón pública, se examinan críticamente las objeciones que, desde el comunitarismo, ha realizado Sandel y, desde el liberalismo, ha planteado Dworkin. Para terminar, se revisa la pertinencia y potencia de tales reproches.

Palabras Clave: Razón pública Doctrina comprehensiva - Liberalismo político - Comunitarismo - Republicanismo cívico liberal.

\section{Abstract}

This article analyzes some critical observations of the idea of public reason as sustained by Rawls. After explaining Rawl's conception of public reason in the introduction, it is critically examined the objections from the standpoint of Sandel's communitarian and from the liberal perspective of Dworkin. Finally, it is revised the pertinence and relevancy of this rebuttals.

KeY words: Public reason - Comprehensive doctrine-Political liberalism - Communitarianism - Liberal civic republicanism.

* Doctor en Derecho por la Universidad Autónoma de Madrid; Profesor de la Escuela de Derecho de la Universidad de Valparaíso. Domicilio postal: Av. Errázuriz 2120, Valparaíso, Chile. Correo electrónico: luis.villavicencio@uv.cl 


\section{INTRODUCCIÓN}

La idea de razón pública, sintéticamente expuesta, alude a un ámbito en el que opera la intersubjetividad, esto es, un dominio en el que lo que vale como razón para mí, debe valer también para los demás -si es que desean contar con mi aquiescencia- y viceversa. Lanzados en un mundo en el que nos encontramos divididos por profundas diferencias respecto de nuestras doctrinas comprehensivas ${ }^{1}$, muchas de ellas irreconciliables, la sensata necesidad de alcanzar los beneficios de la cooperación social conduce a escindir las razones que valen para mí de las que pueden valer para todos, incluso para aquellos que piensan muy distinto.

Es efectivo que cualquier razón es en algún sentido pública, puesto que una de carácter privado cuyas reglas de inferencia sólo valgan para uno mismo es, para los efectos que me interesan, irrelevante. Pero esas razones de cierta forma públicas -como las que regulan una familia o una asociación- lo son exclusivamente para sus miembros y persiguen propósitos diversos a la razón pública que pretende gobernar una sociedad bien ordenada ${ }^{2}$. Mientras una asociación busca fines vinculados estrechamente con la descripción comprehensiva de alguna doctrina completa, la sociedad persigue propósitos políticos que son independientes de cualquier doctrina comprehensiva en particular. En consecuencia, la razón que gobierna una asociación debería depender, por definición, de la adhesión que se preste a los fines que la inspiran. Sin embargo, ello no ocurre con la sociedad en la que cada uno de nosotros ingresa sin poder alejarse de ella, pero que nos demanda igualmente un mecanismo a través del cual podamos explicarnos unos a otros el fundamento de nuestras acciones públicas,

${ }^{1}$ Rawls, John, La Justicia como equidad. Una reformulación (traducción de Andrés DE Francisco, Barcelona, Paidós, 2002), p. 43, define las doctrinas comprehensivas como aquellas doctrinas religiosas y filosóficas a cuya luz se ordenan y entienden los diversos fines y objetivos de las personas.

${ }^{2}$ Utilizo la expresión "sociedad bien ordenada", tal como la acuñó RawLS, La Justicia, cit. (n. 1), pp. 32-33, en su acepción amplia. Para este autor, la idea de una sociedad bien ordenada tiene dos sentidos: uno general y otro particular. El primero se satisface cuando una sociedad es efectivamente regulada por una concepción política y pública de la justicia, cualquiera que ésta sea. El segundo se alcanza sólo cuando los ciudadanos suscriben y saben que todos los demás adhieren la misma concepción de la justicia, por ejemplo, una doctrina específica de los derechos naturales. Rawls advierte que, dado el hecho irremediable del pluralismo razonable en sociedades democráticas, es imposible concebir una sociedad bien ordenada en la que todos sus miembros compartan una misma creencia comprehensiva. Sin embargo, los ciudadanos democráticos, que defienden doctrinas comprehensivas diversas, pueden coincidir en una concepción política de la justicia gobernada por la razón pública. 
de modo tal que cada cual pueda esperar razonablemente que los demás aceptarán ese fundamento. Esa es la cuestión a la que debe enfrentarse la razón pública ${ }^{3}$.

Ahora bien, en el contexto específico de la obra de Rawls, el problema se vincula con la manera en que deben interpretarse y aplicarse, en la vida pública, los principios de justicia. Dado que éstos son afirmados desde diversos puntos de vista comprehensivos, las personas poseen distintos criterios para valorar e interpretar la evidencia. Como no es razonable esperar que todos los sujetos simplemente confíen en los criterios de otros -y dada la manera de concebir a los ciudadanos de una sociedad democrática como partícipes de un cuerpo de personas libres e iguales que ejercen conjuntamente el poder coercitivo del Estado- lo que se necesitan son estándares para valorar las evidencias y los razonamientos que puedan ser compartidos. La solución que Rawls propone es que aquellas cuestiones que involucran el uso del poder coercitivo del Estado, por lo menos las más relevantes, sean resueltas conforme a la razón pública, esto es, en función de motivos y valores que pertenezcan a una concepción política de justicia liberal cuya justificación sea independiente de cualquier doctrina comprehensiva, aplicando formas de argumentación y de investigación, como también métodos de valoración de la evidencia, que sean independientes de esas visiones ${ }^{4}$.

Así pues, y en las propias palabras del filósofo, "la razón pública es la forma de razonamiento propia de ciudadanos iguales que se imponen a sí mismos, como cuerpo colectivo, reglas que cuentan con el respaldo del poder del Estado [...] [L] as pautas de investigación y los métodos de razonamiento compartidos hacen a esa razón pública, al tiempo que la libertad de expresión y pensamiento en un régimen constitucional hacen a esa razón libre. Por el contrario, la razón no pública es la razón propia de los individuos y las asociaciones dentro de la sociedad: les sirve de guía para deliberar de modo bastante adecuado a la hora de tomar sus decisiones personales y colectivas"s.

Con todo, la idea de la razón pública, tal como Rawls la plantea, configura una paradoja que el propio autor reconoce: ipor qué deberían los ciudadanos y ciudadanas respetar los límites de la razón pública cuando discuten y votan sobre las cuestiones políticas básicas? O, más general,

${ }^{3}$ PeÑA, Carlos, Equilibrio reflexivo, constructivismo y razón pública. El problema de la realidad y la justificación en filosofía politica, en Revista de Ciencias Sociales 47 (2002): John Rawls: Estudios en su memoria, pp. 412 y 413.

${ }^{4}$ Seleme, Hugo, Neutralidad y justicia. En torno al liberalismo político de John Rawls (Madrid, Marcial Pons, 2004), pp. 328 y 329.

${ }^{5}$ Rawls, John, La Justicia como equidad, cit. (n. 1), pp. 132 y 133. 
¿cómo podemos considerar razonable para los ciudadanos y ciudadanas, cuando los asuntos más básicos están en juego, limitarse a apelar a una concepción pública de la justicia y no a la verdad global comprehensiva que comparten?6.

Entre la vida privada y la vida pública habría, según Rawls, una cierta discontinuidad debido a que no sería posible extender, como si estuvieran conectadas, mis respuestas a la pregunta de cómo debe ser vivida la vida y el problema de cómo deben ser diseñadas las instituciones sociales básicas. Los asuntos públicos exigirían poner entre paréntesis los ideales de excelencia humana para detenerse exclusivamente en la cuestión acerca de cómo debe organizarse la estructura básica. Así, por ejemplo, alguien podría considerar intrínsecamente malo el aborto y creer firmemente que la vida de una mujer que se practica un aborto se degrada; pero de ello no se sigue -afirma el ideal de la razón pública discontinua- que esa persona deba oponerse a la promulgación de una ley que permita el aborto en las primeras semanas de embarazo, puesto que dicha ley simplemente autoriza la opción para aquellas mujeres que piensan que su vida sería mejor si deciden no llevar a término una gestación. ¿Es correcta esa discontinuidad entre la vida buena y el ámbito de lo público? ¿Por qué razones estaríamos dispuestos a dejar de lado nuestra propia doctrina comprehensiva cuando se discuten en el ámbito público los temas más fundamentales? En lo que sigue, analizaré críticamente dos tipos distintos de objeciones al modelo de la discontinuidad. Por una parte, las críticas que Sandel, desde el comunitarismo, ha desplegado en contra de Rawls; y, por otra, los reproches que Dworkin, desde las propias filas del liberalismo, ha imputado al ideal de

\footnotetext{
${ }^{6}$ Rawls, John, El liberalismo político (traducción de Antoni Domènech, Barcelona, Crítica, 1996), p. 251. Esta paradoja ya había sido expuesta por Wollheim, Richard, A Paradox in the Theory of Democracy, en Laslett Peter - Runciman W. G. (editores), Philosophy, Politics and Society (Oxford, Basil Blackwell, 1967), pp. 7I87). Según el autor, el problema con la institución de la democracia se puede apreciar fácilmente si nos imaginamos a un ciudadano que mantiene entre dos alternativas, la A y la B, que la primera es la que debemos preferir. Sin embargo, la decisión que emana del procedimiento democrático le indica que será la alternativa $\mathrm{B}$ la que finalmente deba aprobarse. ¿Por qué ese ciudadano debiera aceptar esa decisión contraria a sus deseos? Las elecciones que los ciudadanos realizan en una democracia, cuando se les pide que opten por algo, están más cercanas a las decisiones evalua tivas que a las expresiones de deseos y esto no se debe, continúa el autor, a que mantenga una visión particularmente elevada del comportamiento político sino a que cree que los ciudadanos ordinarios enfrentados a una decisión política están mejor capacitados para saber cuál de las dos políticas piensan que deben ["ought to be"] aprobarse más que cuál de ellas quieren ["wants"] que se apruebe. Y esto constituye una paradoja en el corazón mismo de la teoría democrática (Wollheim, cit. ibi, pp. 78 y 79).
} 
razón pública rawlsiano. Para terminar, evaluaré la potencia y pertinencia de esos reparos ${ }^{7}$.

\section{LA PARADOJA DE LA RAZÓN PÚBLICA Y LAS CRÍTICAS DE SANDEL}

La evaluación que Sandel realiza del liberalismo político, en la segunda edición de su obra: Liberalism and the Limits of Justice ${ }^{8}$, plantea varias críticas a la idea de razón pública. El autor comunitarista parte por reconocer que la nueva concepción política de la persona rawlsiana le permite a Rawls rescatar la prioridad de la justicia de argumentaciones sustentadas en una cierta metafísica sobre la naturaleza del yo, pero al costo de tornarse vulnerable a tres nuevas objeciones?

La primera de ellas sostiene que Rawls se ve obligado a apelar a doctrinas comprehensivas, porque muchas veces las disputas dependen de la verdad que se pueda atribuir a una idea comprehensiva. La crítica de Sandel descansa en que, a pesar de la importancia de los valores políticos, Rawls apela también a demandas surgidas desde doctrinas comprehensivas religiosas y morales, no siempre poniéndolas razonablemente entre paréntesis por propósitos políticos. Cuando graves preguntas morales están implicadas -sentencia Sandel- la decisión de si es razonable o no excluir argumentos morales y religiosos por amor a un acuerdo político, dependerá, por lo menos parcialmente, de cuál de las doctrinas morales o religiosas en disputa es verdadera ${ }^{10}$.

Como es bien sabido, el liberalismo político insiste en apartar visiones comprehensivas morales y religiosas en razón de propósitos políticos, manteniendo la separación entre nuestras identidades políticas y personales. La razón descansa en el hecho de que en las sociedades democráticas

${ }^{7}$ Para una aproximación general a la idea de razón pública desde la perspectiva de la propia construcción rawlsiana, puede verse: Larmore, Charles, Public Reason, en Freeman, Samuel (ed.), The Cambridge Companion to Rawls (New York, Cambridge University Press, 2003), pp. 368-393.

${ }^{8}$ SANDel, Michael, El liberalismo y los límites de la justicia (traducción de María Luz Melon, Barcelona, Gedisa, 2000), pp. 184-218.

${ }^{9}$ Sandel, Michael, Liberalism and the Limits of Justice (2a edición, New York, Cambridge University Press, 1998), pp. 195 y 196. Para un análisis detallado respecto de la posibilidad de compatibilizar la concepción política de la persona defendida por Rawls con visiones, como la de Sandel, que defienden una conexión constitutiva entre la identidad y los fines véase: Villavicencio Miranda, Luis, La concepción política de la persona y las visiones constitutivas del bien, en Ideas y Valores 56 (2007) 135, pp. 29-48.

${ }^{10}$ Sandel, Michael, Liberalism, cit. (n. 9), p. 196. 
modernas las personas disienten sobre la vida buena y, por ende, poner entre paréntesis las convicciones comprehensivas es indispensable si se pretende asegurar la cooperación social sobre la base del respeto mutuo. Lo anterior hace surgir una pregunta que, según Sandel, el liberalismo político es incapaz de responder en sus propios términos: aun concediendo la importancia de asegurar la cooperación social sobre la base del mutuo respeto, ¿qué es lo que asegura que ese interés siempre sea tan importante como para valer más que cualquier interés competitivo que podría surgir de puntos de vista comprehensivos morales o religiosos? ${ }^{11}$. Por supuesto, la primera y más segura forma de garantizar la prioridad de una concepción política de la justicia -y, en consecuencia, de la prioridad de lo justo- sería negar la verdad de todas las concepciones morales o religiosas puestas entre paréntesis. Pero esta posibilidad es descartada de inmediato por Rawls, puesto que implicaría que el liberalismo político cae en el tipo de postura filosófica que busca evitar a toda costa. Rawls enfatiza repetidamente que el liberalismo político no depende de un escepticismo sobre las doctrinas comprehensivas morales o religiosas. Con todo, si el liberalismo político admite que alguna de esas doctrinas pueda ser verdadera, ¿qué es lo que asegura que ninguna de ellas pueda tener el peso suficiente para dejar de lado legítimamente los valores políticos?

Sandel emplea dos ejemplos que permiten observar mejor la dificultad de afirmar la prioridad de los valores políticos sin referirse a los argumentos morales o religiosos comprehensivos: uno es el debate contemporáneo sobre el derecho a abortar y el otro es el debate que se produjo entre Abraham Lincoln y Stephen Douglas en torno a la soberanía popular y la esclavitud. $\mathrm{El}$ autor concede que el intenso desacuerdo sobre la permisibilidad moral del aborto transforma en especialmente fuerte el argumento de buscar una solución política que ponga entre paréntesis las cuestiones morales y religiosas en disputa. Mientras esto es razonable por propósitos políticos, para las doctrinas comprehensivas morales y religiosas la apuesta depende, en gran medida, de cuál de esas creencias es verdadera. Si la doctrina de la Iglesia Católica es verídica, si la vida humana es relevante en algún sentido desde el comienzo de la concepción, poner entre paréntesis la pregunta moral-teleológica sobre el comienzo de la vida humana es mucho menos razonable que lo que podrían ser las presuposiciones morales y religiosas rivales. En cambio, si lo más seguro para nosotros es que los fetos son, en un sentido moralmente relevante, diferentes de los bebés, probablemente

${ }^{11}$ Ibíd., p. 196. 
podemos defender una concepción política de la justicia que deje a un lado la controversia sobre el estatus moral del feto ${ }^{12}$.

El caso del debate entre Lincoln y Douglas es similar. En dicha disputa se encontraba en juego, precisamente, la tesis de prescindir de las preguntas morales controvertidas. Douglas sostenía que las personas estaban limitadas por un desacuerdo acerca de la moralidad de la esclavitud y que, en consecuencia, la política nacional debía ser neutral respecto de esta cuestión. La doctrina de la soberanía popular que él defendía no juzgaba la esclavitud como correcta o errada, sino que pretendía dejar a los ciudadanos de cada Estado resolverla libremente de conformidad con sus razonamientos. La única esperanza de que el país permaneciera unido, concluía Douglas, era un acuerdo sobre el desacuerdo, poner entre paréntesis la controversia moral sobre la esclavitud y respetar el derecho de cada Estado de decidir esta cuestión por sí mismos. Lincoln, en cambio, sostenía un argumento contra la concepción de la justicia que planteaba su contendor. Para él, la política debía expresar -antes que evitar- la valoración moral substantiva sobre la esclavitud ${ }^{13}$.

El punto clave que une a ambas ilustraciones es la negación del argumento que busca descartar las cuestiones morales relevantes para alcanzar un acuerdo político. En ambos casos, la plausibilidad del argumento político depende de una respuesta específica a la cuestión moral substantiva que se exige poner entre paréntesis: en el primer ejemplo, la controversia sobre el estatus moral del feto; $y$, en el segundo ejemplo, la moralidad de la esclavitud. Lo que Sandel sostiene es que para poder adoptar una posición política, como la del liberalismo político, debe resolverse previamente cuál de los presupuestos en que se basan las doctrinas comprehensivas razonables es verdadero. Solamente luego de esto podremos determinar si es viable una concepción política, por lo que no se cumplen los presupuestos rawlsianos de que mediante un consenso por superposición se deja la filosofía tal como está.

Demos un paso más: concentrémonos en la disputa sobre la esclavitud. Los liberales podrían replicar, sugiere Sandel, apelando a una concepción liberal de la persona de raigambre kantiana, que es necesario oponerse a la esclavitud porque viola el principio de tratar a los sujetos como fines en sí mismos. Sin embargo, este argumento restituye la idea kantiana de persona $y$, por ende, se encuentra vedado para una concepción política que pretende independizarse de las doctrinas comprehensivas, incluida por cierto la liberal. Entonces, ¿cómo puede el liberalismo político esca-

\footnotetext{
${ }^{12}$ Ibíd., 197 y 198.

${ }^{13}$ Ibíd., pp. 198 y 199.
} 
par del argumento de Douglas y oponerse a la esclavitud sin presuponer una doctrina moral comprehensiva? Puede replicar que Douglas estaba equivocado en buscar una paz social a cualquier precio, puesto que no cualquier acuerdo político es correcto. Aunque se comprenda como una concepción política, la justicia como equidad no es un mero modus vivendi. Dados ciertos principios y autocomprensiones implícitas en nuestra cultura política, solamente un acuerdo que trate a las personas equitativamente, como ciudadanos libres e iguales, puede proveer una base razonable para la cooperación social. Esta respuesta es perfectamente posible ahora, pero no explica cómo el liberalismo político podría haberse opuesto a la esclavitud en 1858, ya que en esa época los ideales implícitos en la cultura política pública no eran incompatibles con ella y, luego, la única respuesta posible -desde una concepción política- era que los Estados podían libremente permitirla o prohibirla ${ }^{14}$. La conclusión parece, entonces, desplegarse naturalmente: si se hubieran aceptado las restricciones impuestas por la razón pública con anterioridad a que los valores políticos liberales se encontraren implícitos en la cultura política pública, el liberalismo, sus principios y sus instituciones nunca habrían llegado a establecerse ${ }^{15}$.

¿Qué se puede decir respecto de esta primera objeción? La crítica de Sandel pareciera que debe comprenderse como si defendiera la idea de que es imposible argumentar a favor del liberalismo, respetando los límites de la razón pública, en una sociedad que no contenga en su cultura política pública, al menos, una concepción liberal de la persona. De modo que si esa cultura es compatible con alguna forma de esclavitud, no existiría forma de argumentar en contra de ella, sin pasar a llevar los límites de la razón pública. Pero Sandel se equivoca, puesto que su análisis pierde de vista que no basta para la validez de un argumento que éste tenga como base las ideas que se encuentran implícitas en la cultura política pública. Además, debe satisfacer el requisito de que sus premisas y conclusiones sean aceptables, tras una debida reflexión, o sea, que se encuentren en equilibrio reflexivo con nuestros juicios meditados de moralidad política.

Si existe implícita en la cultura política pública una idea de ciudadanía que admite dos interpretaciones - una compatible con la esclavitud y otra no- de ello no se sigue que no exista ninguna razón política válida en contra de esa práctica. Al contrario, el argumento más correcto será aquel que interprete dicha idea de la forma que sea más consistente con nuestros juicios de moralidad política. Así pues, la crítica de Lincoln, al revés de lo que postula Sandel, respeta los límites de la razón pública toda vez que

\footnotetext{
${ }^{14}$ Ibíd., pp. 201 y 202.

${ }^{15}$ Seleme, Hugo, Neutralidad y justicia, cit. (n. 4), p. 332
} 
constituye una de las ideas centrales de una concepción política que reposa en una noción de ciudadanía incompatible con la esclavitud, la que aparece como la interpretación más correcta de la idea de ciudadanía implícita en esa sociedad. "Las concepciones políticas son concepciones morales que como tales aspiran a ser correctas. Sostener que la crítica de Lincoln excedía el ámbito de lo político simplemente porque no podía encontrar sustento en las políticas llevadas adelante en su época, es perder de vista el carácter normativo de cualquier concepción política y de los argumentos fundados en ella" 16 . Rawls es especialmente preciso y claro sobre este punto: creer que una concepción política no tiene que ver con lo bueno y lo malo en materia moral es un error y una falsedad. Las concepciones políticas de la justicia son en sí mismas ideas morales y como tales están conformadas por valores normativos. Algunos "pueden pensar que las concepciones políticas relevantes están determinadas por la forma en que un pueblo establece sus instituciones reales: lo político determinado por la política. En esta perspectiva, la prevalencia de la esclavitud en 1858 implica que las críticas de Lincoln eran morales y no políticas. Decir que lo político está determinado por la política puede ser una manera de emplear el término "política". Pero entonces deja de ser una idea normativa y de pertenecer a la razón pública. Debemos aferrarnos a la idea de lo político como una categoría fundamental y a las concepciones políticas como valores morales intrínsecos" ${ }^{17}$.

Pero la posición de Sandel es errada, además, porque se sustenta en una suposición infundada. El autor deduce del hecho de que algunos ciudadanos estuvieran a favor de la esclavitud y otros en contra, que la idea implícita en la cultura política pública del siglo XIX era permisiva al respecto. Sin embargo, esto no es efectivo; lo único que puede concluirse de ese hecho es que existían dos interpretaciones antagónicas de la concepción de persona implícita en la sociedad, una compatible con la esclavitud y otra incompatible, pero ambas igualmente políticas para efectos de su análisis. Luego, para determinar cuál era la correcta, lo relevante no era si estaban elaboradas a partir de las ideas implícitas en la cultura política pública, sino si se encontraban en equilibrio reflexivo con el resto de las convicciones morales. En suma, el argumento de Lincoln sí estaba elaborado a partir de la idea de ciudadanía implícita en la cultura política pública del siglo XIX en Estados Unidos, e intentaba arribar a la interpretación moral más correcta de esa intuición compartida. "El argumento era político, estaba

${ }^{16}$ Ibíd., p. 337.

${ }^{17}$ Rawls, John, Una revisión de la idea de razón pública, en El derecho de gentes (traducción de Hernando Valencia Villa, Barcelona, Paidós, 2001), p. 198. 
elaborado a partir de las ideas implícitas compartidas, y, en consecuencia, respetaba los límites de la razón pública. Sin embargo, también era normativo toda vez que intentaba brindar la interpretación correcta de estas ideas, esto es, una que se encontrara en equilibrio reflexivo con nuestros juicios de moralidad" 18 .

Pasemos ahora a la segunda objeción. Ésta arguye que precisamente porque es verdadero que las personas abrazan en las sociedades modernas democráticas una variedad de puntos de vista religiosos y morales conflictivos, no puede sostenerse que el hecho del pluralismo razonable no deba también alcanzar a las preguntas sobre la justicia. Para el liberalismo político, la prioridad de lo justo se basa en el hecho del pluralismo razonable, pero aquí surge una dificultad: aunque sea cierto, este hecho no es suficiente para sustentarla. La asimetría entre lo justo y el bien depende de una presuposición posterior. Ésta sostiene que, a pesar de nuestros desacuerdos sobre asuntos morales y religiosos, nosotros no tenemos -o no deberíamos tener después de una debida reflexión- similares desavenencias sobre la justicia. El liberalismo político debe asumir no solamente que el ejercicio de la razón humana bajo condiciones de libertad producirá discrepancias sobre la vida buena, sino asumir también que el ejercicio de la razón humana bajo condiciones de libertad no producirá divergencias sobre la justicia ${ }^{19}$.

El problema es -continúa el crítico comunitarista- que esta presuposición no se encuentra justificada. Sólo se necesita mirar alrededor nuestro en las sociedades modernas democráticas para percatarnos que existen abundantes desacuerdos sobre la justicia. Luego, ¿por qué es distinto el hecho del pluralismo razonable sobre las doctrinas comprehensivas del pluralismo razonable sobre la propia justicia? Una posible réplica liberal que Sandel vislumbra es aquella que sostiene que el desacuerdo sobre la justicia es menos fundamental que la disputa sobre las doctrinas comprehensivas y las concepciones sobre la vida buena. Los liberales políticos pueden replicar que hay que distinguir dos formas distintas de discordias sobre la justicia. Hay desacuerdos sobre los principios de justicia que deberían ser y pugnas sobre cómo esos principios deberían ser aplicados. Muchos de nuestros conflictos sobre la justicia, podría sostenerse, son del segundo tipo. Mientras nosotros estamos de acuerdo generalmente, por ejemplo, en que la libertad de expresión es uno de los derechos y libertades básicas, estamos en desacuerdo si el derecho a la libertad de expresión debería proteger los epítetos racistas, las representaciones pornográficas violentas, los anuncios

\footnotetext{
${ }^{18}$ Seleme, Hugo, Neutralidad y justicia, cit. (n. 4), p. 338.

${ }^{19}$ SAndel, Michael, Liberalism, cit. (n. 9), p. 203.
} 
comerciales, o contribuciones ilimitadas a las campañas políticas. Estas diferencias, por vigorosas que sean, son consistentes con nuestro acuerdo al nivel del principio que una sociedad justa debe garantizar un derecho básico a la libertad de expresión.

Sin embargo, ¿es consistente esta distinción? Consideremos como ejemplo el debate sobre el estatus moral de la homosexualidad, una disputa sobre doctrinas morales y religiosas comprehensivas. El liberalismo político insiste en que ninguno de los puntos de vista sobre la moralidad sexual debe jugar un rol en los debates públicos sobre la justicia o los derechos. El gobierno debe ser neutral respecto de ellos. Esto significa que a aquéllos que les repugnan ciertas opciones sexuales no pueden pretender que la ley defienda su perspectiva, y quienes defienden los derechos de los homosexuales no pueden argumentar que la homosexualidad es moralmente defendible. Desde la perspectiva del liberalismo político, cada una de estas aproximaciones podría basar erróneamente los derechos en alguna concepción del bien. Pero, para el crítico comunitarista, es posible razonar sobre el bien del mismo modo que sobre lo justo y, por ende, la pretensión del liberalismo político de defender la prioridad de lo justo y, por ańadidura, la asimetría entre lo justo y lo bueno es débil y arbitraria ${ }^{20}$.

Con todo, la objeción otra vez se equivoca. La respuesta que Rawls daría a alguien que se empecinara en imponer a otros lo que él considera verdad, sería sencillamente que esa persona no está reconociendo a la sociedad como una empresa cooperativa sustentada en la idea de reciprocidad y que, en consecuencia, actúa de manera irrazonable; pero no reposaría en ningún examen de fondo sobre la doctrina comprehensiva que esa persona suscribe, ni en una prioridad de lo justo basada en que sólo podemos razonar sobre asuntos políticos, sino simplemente en la afirmación de que el poder coercitivo del Estado debe encontrar una justificación legítima. Éste debe sustentarse en razones que los demás puedan aceptar de forma consistente con la libertad e igualdad que se reconocen mutuamente los miembros de una sociedad democrática, o sea, de acuerdo a lo que el filósofo llama el deber de civilidad ${ }^{21}$. Bajo las condiciones del desacuerdo razonable, la justificación del poder estatal sólo puede lograrse apelando no a la propia doctrina comprehensiva, sino a argumentos que sean aceptables por todas las personas razonables. "[S]abiendo que sostienen una diversidad de doc-

${ }^{20}$ Ibíd., pp. 207-210.

${ }^{21}$ El deber de civilidad es, en otras palabras, un arquetipo de la ciudadanía que "nos exige que, a su debido tiempo, defendamos la legislación y las políticas públicas que apoyamos apelando a razones públicas o a los valores políticos amparados en la concepción política de la justicia”, según Rawls, John, La Justicia, cit. (n. 1), p. 131. 
trinas religiosas y filosóficas razonables, los ciudadanos deberían ser capaces de explicarse unos a otros el fundamento de sus acciones en términos tales que cada uno pudiera razonablemente esperar que los demás aceptaran como consistentes"22.

Así pues, respetar los límites de la razón pública no significa comprometerse con la idea de que los valores políticos son más importantes que aquellos que forman parte de cualquier doctrina comprehensiva, incluso de la propia visión que se profesa; implica simplemente distinguir los planos: los valores que pertenecen a una doctrina comprehensiva, por más importantes que éstos puedan parecernos en comparación con los valores políticos, si la doctrina es razonable, nunca estarán en conflicto con ellos por pertenecer a dominios distintos ${ }^{23}$.

En fin, la tercera y última objeción sostiene que la exclusión de las convicciones religiosas o morales empobrece el discurso político. Si es posible razonar sobre el modo de ponernos de acuerdo sobre cualquier controversia moral o política, no es algo que podamos dilucidar sin antes haberlo intentado. Así, por ejemplo, en el caso de la homosexualidad, si alguien se opone a la postura que pretende condenarla mediante leyes que la repriman, lo único que podría decir es que tales leyes son malas porque se fundan en una cierta concepción de la vida buena, pero no podría argumentar en el sentido de demostrar que la homosexualidad es moralmente permisible y que, por ende, la concepción de la vida buena que lo niega está equivocada, lo que indudablemente, concluye el autor, empobrece el discurso político ${ }^{24}$.

Estas restricciones que la razón pública impone al debate político acarrean dos tipos de costos: los morales y los políticos. El coste estrictamente moral depende de la validez y la importancia de las doctrinas religiosas y morales que la razón pública liberal exige dejar a un lado cuando decidimos cuestiones sobre la justicia. Éstos variarán necesariamente caso a caso, siendo muy altos cuando una concepción política de la justicia autoriza que se tolere un grave error moral y nulo en el caso contrario. Así, por ejemplo, si tomamos el debate sobre el aborto, el costo moral de poner entre paréntesis la doctrina católica (que defiende esencialmente que el feto es una persona desde el momento de la concepción) será alto si ésta es correcta, y de otra manera será muy bajo. Esto sugiere que, aun considerando la importancia moral y política de la tolerancia, el argumento para aceptar cualquier práctica depende de su evaluación, como así también

\footnotetext{
${ }^{22}$ Rawls, John, El liberalismo politico (traducción de Antoni Domènech, Barcelona, Crítica, 1996), p. 252.

${ }^{23}$ Seleme, Hugo, Neutralidad y justicia, cit. (n. 4), pp. 339 y 340.

${ }^{24}$ SANDEL, Michael, Liberalism, cit. (n. 9), p. 213.
} 
del bien de dejar de lado el conflicto social o que las personas decidan por sí mismas ${ }^{25}$.

Pero, además del costo moral, se configura también uno de tipo político. Las decisiones públicas que sitúan entre paréntesis doctrinas morales y religiosas tan intensamente generarán descontento. Cuando la discusión política carece de resonancia, el deseo por una vida pública con mayor significado produce expresiones indeseables, como los fundamentalismos que tanto temen los liberales ${ }^{26}$.

Sobre esta última objeción, y centrándome en el ejemplo del aborto, se puede señalar que la crítica sandeliana no es decisiva, puesto que es posible sostener que la vida comienza desde la concepción y, al mismo tiempo, que es irrazonable imponer esta convicción a otros. La clave es percatarse que lo irrazonable no es la convicción misma, sino su imposición. "Lo que tiene que ser verdadero para que exista un costo moral es el precepto que sostiene que «es deber de cualquier católico hacer que los demás cumplan, aunque sea obligados por la coacción estatal, con las exigencias que su doctrina prescribe», no simplemente, como sostiene Sandel, que "la vida comienza desde la concepción y, por lo tanto, no se debe abortar". Sólo en el primer caso un católico que no impusiera a otros su convicción respecto al aborto estaría contraviniendo un precepto de su religión. Pero también lo estaría contraviniendo, por ejemplo, si no exigiera que todos sus conciudadanos asistan los domingos a sus oficios religiosos, o profesen que Cristo es el hijo de Dios"27.

Ahora bien, sobre los costos políticos, claramente el debate público no se vacía de contenido moral porque la concepción política de la justicia como equidad no descanse en una visión comprehensiva compartida, puesto que -como ya se dijo- la concepción política siempre ha reposado en argumentos morales, por mucho que Sandel se empeñe en afirmar lo contrario. El error del autor comunitarista es creer que la única clase de concepciones morales son aquellas que versan sobre la vida buena.

\section{EL PROBLEMA DE LA DISCONTINUIDAD ENTRE LA ÉTICA Y LA POLÍTICA: LA ALTERNATIVA DEL LIBERALISMO INTEGRADO}

Las críticas a la idea de la discontinuidad rawlsiana no sólo han provenido desde las filas comunitaristas, sino también desde las propias huestes liberales, particularmente en los últimos trabajos de Dworkin. En este apartado sólo quiero esbozar, muy brevemente, la forma en que este autor

\footnotetext{
${ }^{25}$ Ibíd., pp. 215-216.

${ }^{26}$ Ibíd., p. 217.

${ }^{27}$ Seleme, Hugo, Neutralidad y justicia, cit. (n. 4), p. 342.
} 
reacciona explícitamente, por un lado, a las críticas comunitaristas y, por otro, de forma más bien implícita, a la estrategia de la discontinuidad de Rawls. Dworkin, en clave liberal, ha intentado reconstruir sus tesis siendo especialmente sensible a ciertas objeciones de índole comunitarista, particularmente aquélla que él denomina el argumento de la integración, sentando las bases de lo que él mismo ha llamado liberalismo ético o republicanismo cívico liberal ${ }^{28}$.

Dworkin comienza sus Conferencias Tanner $^{29}$ exponiendo las razones que lo llevan a distanciarse de Rawls y su intento de fundar un liberalismo antiperfeccionista echando mano a argumentos estrictamente políticos, táctica que denomina la estrategia de la discontinuidad en razón de que incluye una separación tajante entre la ética y la política. Obviamente, a primera vista, debido a que uno de los pilares fundamentales de la filosofía liberal es la tolerancia y la neutralidad frente a ideales éticos divergentes, resulta aconsejable que los liberales sustenten ese compromiso de forma que no dependa de un ideal político concreto.

El problema es que ese distanciamiento y esa imparcialidad son totalmente extraños a nuestra forma ordinaria de vivir. Como agentes morales estamos, al menos parcialmente, ligados a algunos valores e ideales específicos y, aún más, nos sentimos satisfechos de comportarnos de esa manera. "Nuestros compromisos, nuestros vínculos y nuestra parcialidad no sólo caracterizan a nuestra forma de ser, sino a la forma como creemos que debemos ser. Como la política forma parte de nuestra existencia, parece totalmente natural que proyectemos estos puntos de vista en la actividad política (...) Un liberalismo que separase la ética de la política nos obligaría a prescindir de nuestras más profundas convicciones" ${ }^{30}$. El liberalismo se asemeja, en consecuencia, a una política de la esquizofrenia ética y moral; parece pedirnos que nos transformemos, cuando discutimos asuntos políticos, en personas incapaces de reconocernos a nosotros mismos, en una

${ }^{28}$ Dworkin, Ronald, Ética privada e igualitarismo politico (traducción de Antoni Doménech, Barcelona, Paidós, 1993); El mismo, La comunidad liberal (traducción de Claudia Montilla, Santafé de Bogotá, Universidad de los Andes, 1996); EL Mismo, Sovereign Virtue. The Theory and Practice of Equality (London, Harvard University Press, 2000), pp. 211-284. Para una aproximación crítica a las tesis centrales de Dworkin, véase: Burley, Justine (editora), Dworkin and his Critics (Blackwell Publishing, 2004), pp. 70-109.

${ }^{29}$ Publicadas en su obra Ética privada, cit. (n. 28).

${ }^{30}$ Mulhall, Stephen - Swift, Adam, El individuo frente a la comunidad. El debate entre liberales y comunitaristas (traducción de Enrique López Castellón, Madrid, Temas de Hoy, 1996), p. 363. 
especie de criaturas políticas completamente diferentes de los individuos corrientes que eligen por sí mismos en su vida cotidiana ${ }^{31}$.

Rawls podría defender su estrategia de la discontinuidad argumentando que la concepción política que escinde el ámbito público de lo no público se justifica debido a que los ciudadanos y ciudadanas tienen buenas razones para suscribir ese punto de vista político, que no coincide específicamente con ninguna perspectiva personal, con el fin de asegurar la cooperación social. Pero el problema consiste, precisamente, en identificar las razones que podrían llevar a las personas a prestar su apoyo a ese enfoque político. Las opciones son dos: por un lado, la obligación de actuar razonablemente cuando se afecta a otros; y, por otro, el deber de observar unos principios que están latentes en la cultura política pública. La crítica de Dworkin a la primera opción es sencillamente que mi "idea de lo que no sería razonable que alguien rechazara refleja mis convicciones sobre qué formas de vida son buenas o malas y mis puntos de vista sobre la equidad"32, es decir, la idea de que lo que es razonable se encuentra permeada por la concepción del bien que posee cada individuo. A su turno, el reproche a la segunda opción es igualmente claro: la historia de una comunidad política no sólo está compuesta por tradiciones, sino también por disputas y polémicas, por lo que resulta muy difícil lograr reconstruir una interpretación de una tradición sin contradicciones. Específicamente, “dos concepciones políticas muy distintas que justificaran hoy en día decisiones políticas controvertidas muy diferentes podrían cuadrar de forma casi idéntica con los documentos y la retórica de la historia política de una comunidad" 33 .

En suma, Dworkin está convencido que cualquier intento de justificar el antiperfeccionismo liberal recurriendo a la estrategia de la discontinuidad tiene que hacer frente a escollos insalvables y, por ello, el giro político de Rawls queda expuesto a la crítica desarrollada por el autor ${ }^{34}$.

${ }^{31}$ Dworkin, Ronald, Ética privada, cit. (n. 28), p. 57.

${ }^{32}$ Ibíd., p. 75.

${ }^{33}$ Ibíd., p. 81.

${ }^{34}$ Otro filósofo que niega la estrategia de la discontinuidad es Raz. Este autor se diferencia de Rawls respecto a las dos formas de entender la neutralidad: niega la distinción entre lo político y lo no político (al igual que Dworkin) y, además, permite que el Estado formule juicios de valor sobre los distintos modos de vida, lo que lo aleja, a la vez, de Rawls y de Dworkin. La tesis central del filósofo inglés es una defensa perfeccionista del valor de la autonomía, o sea, la vida autónoma sólo es valiosa cuando se dedica a perseguir proyectos y a entablar lazos aceptables y valiosos. En particular, Raz busca refutar tres argumentos que se aducen para rechazar el perfeccionismo: i) admitir ideales controvertidos significa que las creencias de unos desautorizan las de otros; ii) la política perfeccionista implica que unos grupos imponen sus formas de vida a otros; y iii) consentir que los gobiernos adopten me- 
Veamos ahora cómo Dworkin despliega su liberalismo comprehensivo antiperfeccionista.

DwOrkin plantea que de todas las críticas comunitaristas, una de ellas es especialmente plausible, la que identifica como el argumento de la integración. Según el autor, la premisa fundamental de esta tesis es correcta: las comunidades políticas disfrutan de una vida comunal cuyo éxito o fracaso forma parte de lo que determina si las vidas de sus miembros son mejores o peores. Es decir, la tolerancia liberal se sostendría en una distinción ilegítima entre lo justo y el bien, entre la moralidad pública y la privada. De este modo, descree de lo que él denomina la estrategia de la discontinuidad -aquella que escinde las cuestiones de moralidad pública y privada- propia de las teorías liberales contractualistas y propone, alternativamente, una estrategia de la continuidad que diluye la escisión apuntada.

En esa misma línea, el filósofo estadounidense intenta fundar una especie de republicanismo cívico liberal que se sustenta en una aceptación débil del argumento de la integración. O sea, su noción de comunidad se aparta de la versión ontológica fuerte del comunitarismo metafísico, que sucumbe al antropomorfismo y supone que una vida comunal es la vida de una persona a tamaño grande (afirmando que la integración depende de la primacía ontológica de la comunidad), para estructurarse desde un punto de vista de las prácticas sociales que articulan las comunidades y sus actividades.

Para explicar esta especial forma de comprender la integración desde un punto de vista liberal, Dworkin echa mano a la analogía que también

didas perfeccionistas implica una actitud moral puritana, que reprime toda forma de vida que no se aprueba moralmente. Véase: Raz, Joseph, The Morality of Freedom (Oxford, Oxford University Press, 1986), pp. 110-162 y 369-429. Para una presentación general de la obra de Raz desde la perspectiva del debate liberal-comunitarista, véase: Mulhall, Stephen - Swift, Adam, El individuo frente a la comunidad. El debate entre liberales y comunitaristas (traducción de Enrique López Castellón, Madrid, Temas de Hoy, 1996), pp. 403-450. Sobre la postura perfeccionista de Raz sólo quisiera dejar planteada una idea: me parece que la tesis de Raz es inocua. Si, según el autor inglés, el ejercicio de la autonomía sólo es valioso cuando se dedica a perseguir proyectos meritorios, pero igualmente, en los hechos, la decisión de seguir o no una determinada forma de vida valiosa queda entregada a la decisión autónoma de cada sujeto, me pregunto si la postura de Raz es, en la práctica, relevante. $\mathrm{O}$ sea, si los liberales nunca han negado que la autonomía del individuo se encuentra influenciada por el peso de la herencia de las tradiciones, por influencias externas, incluso por concepciones objetivistas del bien, pero, con todo, lo decisivo es que la decisión autónoma sea constitutiva y no meramente aditiva, o sea, que es valiosa con prescindencia de las opciones tomadas, el resultado entre la lógica liberal y la de Raz es equivalente, no presenta diferencias relevantes. 
utilizara Rawls de la vida común de una orquesta ${ }^{35}$. Si bien una orquesta es una unidad de acción o agencial y, por consiguiente, los músicos consideran sus actuaciones como un todo y participan de los triunfos y fracasos de la orquesta como si fueran los suyos propios, esto no significa que al primer violinista le importen las conductas sexuales del percusionista y si, de hecho le preocuparan, lo haría motivado por fines puramente altruistas o de otro tipo, pero no constituiría una inquietud por la buena salud de la orquesta, puesto que la integridad de la orquesta no se ve nunca comprometida por el adulterio del percusionista. La orquesta tiene, por supuesto, una vida común, pero ésta se reduce exclusivamente a una vida musical. Del mismo modo, la vida colectiva de una comunidad sólo incluye los actos considerados colectivos por las prácticas y actitudes que crea la comunidad como agente colectivo. Así, esta vida común incluye los actos políticos formales, es decir, los actos de un gobierno a través de sus instituciones legislativas, ejecutivas y judiciales, los que son suficientes para satisfacer todas las condiciones de la agencia colectiva que identificamos cuando consideramos las razones por las cuales una orquesta tiene vida comunal.

Si la vida de una comunidad se limita a las decisiones políticas formales, si su éxito crítico depende, por tanto, sólo del éxito o fracaso de sus decisiones legislativas, judiciales y ejecutivas, se puede aceptar, sin temor, la primacía ética de la vida de la comunidad sin abandonar o comprometer la tolerancia liberal y la neutralidad acerca de lo que sea una buena vida. Pero, ¿cómo es posible llegar a estas conclusiones clásicamente liberales aceptando el argumento de la integración? La respuesta se encuentra en el diseño de lo que Dworkin llama el modelo del desafío. El objetivo del autor es ofrecer, como ha quedado de manifiesto del esquema precedente, una teoría ética capaz de sustentar los principios de un liberalismo igualitarista sin dividir nuestra ética personal de nuestra dimensión política; o sea, proponiendo una estrategia de continuidad. Este tipo de táctica, en opinión del filósofo, pretende alcanzar la neutralidad como resultado del argumento y no como un presupuesto metodológico que obliga a los agentes a suscribir categóricamente principios normativos basándose en razones no morales. El objetivo pone a Dworkin en pie forzado: debe ser capaz de construir una concepción que sea lo suficientemente abstracta para permitir arribar al principio de la tolerancia liberal pero, al mismo tiempo, autorice la evaluación crítica de los distintos modos de vida. Combinando el modelo continuista del desafío y la distinción entre interese críticos y volitivos, el autor fundará su respuesta.

${ }^{35}$ Rawls, John, El liberalismo político, cit. (n. 6), p. 238; El mismo, La Justicia como equidad, cit. (n. 1), p. 111. 
Definamos, entonces, qué entiende Dworkin por intereses críticos y por intereses volitivos. Los primeros, serían aquellos que se refieren a los logros y experiencias que deberíamos desear ya que, de no satisfacerlos, nuestra vida perdería parte de su valor, sería objetivamente peor (puede apreciarse el carácter claramente normativo de este tipo de intereses). Los segundos, son aquellos logros o experiencias que de hecho deseamos, pero no consideramos que nuestra vida sea peor objetivamente por no alcanzarlos. El bienestar volitivo se incrementa cada vez que uno alcanza algo que desea; por ejemplo, para mí, disfrutar el Nisi Dominus de Vivaldi constituye una fuente considerable de placer. A su turno, el bienestar crítico aumenta cuando uno alcanza algo que debe desear, es decir, conquistas cuya falta significaría un empeoramiento de mi vida; por ejemplo, yo espero seguir teniendo una excelente relación con mi esposa, no porque eventualmente lo desee sino que porque creo, objetivamente, que mi vida sería peor sin ella.

Por otra parte, Dworkin distingue el modelo del desafío por oposición a lo que él denomina el modelo del im pacto. El primero ubica el valor de una vida buena en el valor que es inherente a la realización de una existencia conseguida; es decir, vivir una vida éticamente valiosa consiste en una particular versión adverbial del bien (praxis aristotélica) que se asienta en enfrentar el desafío de la autobiografía como un ejercicio diestramente realizado más que apreciado por su resultado. En cambio, el segundo, otorga valor a una vida cuando sus consecuencias acarrean un impacto, una repercusión objetiva sobre el mundo, estableciendo una concepción del bien identificada por sus efectos u obras (poiesis aristotélica) que se pesan, positiva o negativamente, en comparación con los impactos ejecutados por otras vidas. En opinión del autor en análisis, el modelo del desafío nos permite evaluar mejor el modo en que cualquiera de nosotros califica sus existencias. Yo, a modo de ilustración, intento porfiadamente tocar el piano o escribir un poema que valga la pena, careciendo en absoluto de talento para la música y para la poesía. Podría cuestionarme, muy razonablemente, esta torpe persistencia habiendo en el mundo miles de magníficos pianistas y poetas. Mi tozudez sólo tiene sentido en cuanto conciba mi propia biografía como un reto que se satisface en el propio ejercicio llevado adelante con destreza. Como se ve, el modelo del desafío se encontraría mucho mejor preparado para evitar el peligro elitista de calificar como valiosas sólo las vidas exitosas y, a la vez, tiene la ventaja formal de desvincular el valor de una vida de sus productos y fundar en el interés propio el principio normativo de tratar a los demás de modo equitativo.

Con todos estos elementos, el autor estadounidense concluye que el 
modelo del desafío permite acoger distintas concepciones substantivas del bien, siempre que se sometan a determinadas restricciones derivadas de los intereses críticos. O sea, los principios políticos son normativos en el mismo sentido en que lo son los intereses críticos: unos definen la comunidad política a la que deberíamos aspirar y, los otros, el modo en que deberíamos vivir en ella. Dworkin, en suma, pretende desplegar una conexión entre la ética y la justicia, mostrando que la concepción que desarrollemos de la segunda pertenece al ámbito de los intereses críticos que tienen los liberales éticos; que este tipo de intereses confieren significado a un modelo de vida deseable; y que las personas, aun sosteniendo concepciones del bien diversas, acabarán eligiendo los principios del liberalismo igualitario, esto es, el principio de neutralidad y la igualdad de recursos como criterio distributivo.

En fin, Dworkin defiende el valor intrínseco de la autonomía sin subordinarla a la excelencia de las preferencias seleccionadas. Para el profesor estadounidense, la vida de una persona puede ser evaluada de dos formas diversas: una concepción posible, a la que llama aditiva, sostiene que la existencia de un sujeto puede ser calificada como buena o mala sin consultarle su opinión al respecto; la otra concepción -constitutiva- postula que ningún componente podría aportar al valor de la vida de un individuo, a menos que sea percibido como tal. Esto quiere decir que, aunque yo considere que la existencia de otra persona -por ejemplo una amiga a la que le tengo mucho aprecio- está siendo desperdiciada y tuviere la convicción de que su vida mejoraría notablemente si fuera coaccionada a darle a ésta un giro, debo renunciar a realizar o justificar algún tipo de imposición sobre ella. Para el punto de vista aditivo, los componentes de una vida buena son independientes de la confirmación de tales componentes. Al contrario, para el punto de vista constitutivo, ningún componente contribuye al valor de una existencia si no existe una confirmación genuina por parte del propio sujeto. Dworkin considera que existen fuertes razones para preferir la última noción. El punto de vista aditivo no es capaz de explicar por qué una buena vida es definitivamente valiosa para la persona que la vive y, además, es inverosímil que alguien pueda llevar una vida mejor si esto significa contradecir sus más profundos ideales éticos ${ }^{36}$.

Dworkin pretende, en definitiva, defender la neutralidad no como un

${ }^{36}$ Dos ejemplos de Dworkin, Ronald, Ética privada, cit. (n. 28), pp. 107 y 108, me servirán para ilustrar el punto: i) si un misántropo es muy querido, pero desprecia el amor de los demás como si no fuera valioso, su vida no vale más la pena por ser querido; ii) aunque algunos piensen que la religión debe ser parte de una vida bien llevada, ¿podría mejorar la vida de una persona si se le presiona a observar una vida religiosa que no le merece la pena? 
axioma sino como una conclusión. Así pues, el liberalismo ético, al estar comprometido con el valor de la integridad individual, no puede admitir ningún paternalismo que suponga reducir las elecciones de que disponga la gente; pero, con el fin de preservar la riqueza del marco cultural, sí puede apoyar las medidas que busquen asegurar un mayor margen de elección. Para el autor, los sujetos tendrán una vida más valiosa en cuanto más rica sea su cultura, ya que se aumenta el espectro de las opciones posibles que las personas pueden hacer suyas constitutivamente. Sin embargo, ¿se puede entender la idea de riqueza de modo neutral? Pareciera que no. Resulta muy difícil trazar alguna línea divisoria entre las versiones antiperfeccionistas y perfeccionistas del liberalismo, si al Estado le está permitido apoyar el marco cultural, por ejemplo, subvencionando determinadas actividades artísticas como la ópera o el teatro ${ }^{37}$.

Ahora bien, respecto de la capacidad del modelo del desafío para ser suscrito por personas que postulan muy diversas concepciones del bien, nos enfrentamos a dificultades, porque al final queda expuesto a la misma crítica que Rawls: quien no acepta el liberalismo es considerado como un sujeto irrazonable. El propio Dworkin lo reconoce al señalar que el modelo del desafío: "recoge intuiciones éticas que tenemos casi todos. Las capta, además, de forma más satisfactoria que las concepciones rivales sobre la naturaleza del valor ético, y resuelve cuestiones y dilemas de esas intuiciones que dichas concepciones rivales no pueden resolver. Por eso este modelo debiera resultar atractivo a la gente" ${ }^{38}$.

Queda claro, entonces, que por más que uno pudiera compartir el optimismo de Dworkin, es complicado no imputarle al filósofo que su postura se reduce a afirmar que es sumamente razonable aceptar el liberalismo integrado que nos presenta y que, en consecuencia, no debe considerarse razonable en última instancia a todo aquel que lo rechace. El problema es que en ese caso la defensa de la integración que hace Dworkin parece no diferenciarse de la estrategia de la discontinuidad liberal que había condenado tan tajantemente, pues recurre también a la noción de lo razonable. Dworkin parece así "vulnerable a la crítica que él mismo había hecho previamente a esa estrategia, a saber, que apela a una concepción de «lo razonable» que es inevitablemente sustantiva, y no abstracta y neutral como exige el liberalismo antiperfeccionista" ${ }^{39}$.

${ }^{37}$ Mulhall, Stephen - Swift, Adam, El individuo frente a la comunidad, cit. (n. 34), pp. 391-401.

${ }^{38}$ Dworkin, Ronald, Ética privada, cit. (n. 28), p. 192. El énfasis es mío.

${ }^{39}$ Mulhall, Stephen - Swift, Adam, El individuo frente a la comunidad, cit. (n. 34), p. 400. Para la opinión de Rawls sobre la tesis de Dworkin, véase: Dworkin, Ronald, La comunidad liberal (traducción de Claudia Montilla, Santafé de Bogotá, 


\section{CONCLUSIÓN}

A riesgo de simplificar el complejo y diferenciado tratamiento que Rawls da a la idea de razón pública, y apoyándome esta vez en McCarthy ${ }^{40}$, los puntos centrales de su planteamiento pueden ser resumidos como sigue: i) los límites de la razón pública se aplican a la discusión de los asuntos políticos fundamentales, esto es, a las materias que tienen relación con las esencias constitucionales y la justicia básica; ii) dichos límites operan restringiendo el debate al ámbito de una concepción política de la justicia y de valores políticos fundados en el consenso por superposición de una sociedad bien ordenada. En otras palabras, en las discusiones públicas de los asuntos fundamentales, las razones sostenidas por los bandos opuestos deben ser aquellas que todos podemos razonablemente esperar que serán suscritas, en vista de una concepción política de la justicia compartida. Dicho negativamente, estas razones no deben ser propias de una doctrina comprehensiva moral, religiosa o filosófica; iii) el coto impuesto por la razón pública incluye tanto restricciones de método como de contenido; y iv) junto con esta idea de las fronteras de la razón pública hay un ideal de ciudadanía en el cual, por así decirlo, éstas son internalizadas. En su corazón se ubica el deber de civilidad, a través del cual los ciudadanos se ven a sí mismos como obligados a usar la razón pública en las controversias sobre cuestiones básicas de justicia.

He revisado en las páginas precedentes, dos grupos de reparos que pueden hacerse a esa idea de razón pública. El primero reúne una serie de críticas expuestas por Sandel, que ahora resumiré. Para el autor comunitarista, en primer lugar, no es posible defender una concepción liberal (que respete los límites de la razón pública) al interior de una sociedad que no abrace, previamente, una matriz liberal de la persona dentro de su cultura política. Por lo que si ésta fuera compatible con cualquier forma de esclavitud, no habría modo de argumentar en contra de ella sin traspasar las estrechas fronteras de la razón pública. En segundo lugar, Sandel sostiene que el hecho del pluralismo razonable también afecta a las disquisiciones sobre la justicia, y no sólo a las cuestiones sobre la vida buena. Y, en tercer lugar, el filósofo advierte que la exclusión del debate público de las doctrinas comprehensivas lo empobrece moral y políticamente. Ninguna de esas críticas, como he visto, es concluyente. La primera pasa por alto que una concepción política de la justicia es moral. Por ende, no basta para su validez que ésta se sustente en las creencias subyacentes presentes

Universidad de los Andes, 1996), pp. 245 y 246.

${ }^{40}$ McCarthy, Thomas, Kantian Constructivism and Reconstructivism: Rawls and Habermas in Dialogue, en Ethics 105 (1994) 1, pp. 44-63. 
en la sociedad, si no satisface también el requisito de que sus premisas y conclusiones alcancen un equilibrio reflexivo con nuestros juicios morales debidamente considerados. La segunda, a su turno, se excede, pues respetar los límites de la razón pública no exige defender la tesis de que los valores políticos sean más relevantes que las doctrinas comprehensivas. En vez de eso, sólo nos demanda separar los planos. Si una doctrina es razonable no entrará en pugna con la concepción política, pues la justificación del poder coercitivo del Estado sólo puede lograrse apelando a argumentos aceptables para todas las personas razonables. La tercera, por último, tampoco es convincente, ya que el liberalismo político no requiere que los sujetos no defiendan convicciones morales comprehensivas, sólo reclama que nos abstengamos de imponerlas a otros puesto que sería irrazonable.

El otro grupo de reparos aglutina los reproches que Dworkin ha desplegado en contra del liberalismo político. En esencia, este autor plantea que el problema de la estrategia de la discontinuidad, propia del liberalismo político, no es tanto el método de evitación sino las razones que nos llevarían a aceptarlo y el modo en que arribamos a los principios de justicia. En efecto, la maniobra rawlsiana no puede zafarse de la crítica que nos recuerda que aquello que vamos a considerar razonable se encuentra irradiado por la concepción del bien que poseamos y, en consecuencia, la tan preciada neutralidad liberal no puede ser un axioma -como lo es para Rawls- sino una conclusión contingente del argumento. Sin embargo, como se vio, es una cuestión bien discutible si la teoría fuertemente comprehensiva de Dworkin es capaz de generar el necesario consenso y estabilidad en sociedades modernas, cada vez más fragmentadas. Y, además, al liberalismo integrado dworkiniano también se le cuela -al final de cuentas- la idea de que es irrazonable, dadas las características del modelo del desafío y la noción de intereses críticos, no suscribir principios liberales.

En este escenario, al liberalismo -ya sea continuo o discontinuo- no le queda otra salida que bajar del pedestal de la neutralidad epistemológica, para competir como una teoría más en el mercado de las éticas disponibles. El colofón no puede ser distinto ya que, de otra forma, la teoría liberal dejaría formidables cuestionamientos sin una respuesta adecuada. Cuando ciudadanas y ciudadanos exponemos públicamente nuestras diferencias respecto a cuestiones básicas de justicia que están arraigadas en nuestras diversas doctrinas comprehensivas, ¿podemos eliminar del debate un examen público de las mismas consideraciones que lo sustentan? ¿Pueden los individuos esperar razonablemente divorciar sus creencias privadas de los valores públicos, hasta el punto que exige un ideal de ciudadanía que -de acuerdo con la pretendida neutralidad liberal- demanda que ni siquiera votemos según nuestras conciencias en asuntos políticos fundamentales? 
¿Podemos imaginar una cultura política en la cual, por una parte, los ciudadanos forman sus opiniones leyendo, escuchando e involucrándose en discusiones abiertas sobre las cuestiones políticas básicas, pero luego son compelidos a participar en campañas electorales y apoyar programas legislativos y políticas públicas en razón de fundamentos distintos? Si lo anterior es claro, no hay forma de erigir barreras institucionales entre el océano de opiniones no oficiales y la formación de la voluntad y las islas de un discurso oficial o cuasi-oficial; ni existe modo alguno de construir filtros institucionales que puedan descartar del escenario todas las creencias y valores controvertidos ${ }^{41}$.

Ahora bien, todo lo expuesto hasta ahora no implica que el liberalismo, despojado de su superioridad conceptual, no sea una respuesta atractiva -insisto, como una ética más- a los desafíos que nos impone la convivencia de doctrinas contrapuestas al interior de las democracias constitucionales modernas. Muy por el contrario, la doctrina liberal interpreta, en mi opinión de la manera más adecuada, nuestra propia autocomprensión como herederos de una tradición ilustrada doblemente corregida en cuanto es, por un lado, poscreyente, ya que ha aplicado la tolerancia a su propio sistema de creencias y, por otro, reflexiva, pues se piensa a sí misma como capaz de situarse en la perspectiva de otros agentes morales, poniéndose en sus lugares con el objeto de tomarse el mundo moralmente en serio ${ }^{42}$.

Un ejemplo nos permitirá justificar con suficiente persuasión ese optimismo ${ }^{43}$. Uno de los temas en los que resulta más difícil pensar que el liberalismo nos ofrece razones suficientemente convincentes para suscribir sus tesis normativas -en particular la distribución de lo que Dworkin llama una concepción constitutiva de la autonomía- es el caso de aquellas doctrinas comprehensivas que asignan carácter constitutivo a sus vínculos y fines ${ }^{44}$, como es la noción de persona comunitarista que suscribe Sandel o MacIntyre. El liberalismo puede perfectamente conceder que las personas se constituyen en parte por sus lazos comunitarios, aunque resulta desproporcionado suscribir la tesis de que el contexto en el que vivimos defina totalmente nuestra identidad. Si así fuera, no podría haber personas -como de hecho las hay- nacidas y formadas en horizontes de sentido, por ejemplo, férreamente religiosos, que reflexionan sobre ellos, se distancian

${ }^{41}$ Ibíd., pp. 51-52..

${ }^{42}$ Thiebaut, Carlos, Vindicación del ciudadano. Un sujeto reflexivo en una sociedad compleja (Barcelona, Paidós, 1998), pp. 259-282.

${ }^{43}$ Cfr. Villavicencio Miranda, Luis, La concepción politica, cit. (n. 9), pp. 2948.

${ }^{44}$ Con ello me refiero a aquellas personas que suscriben ideales y creencias con los cuales no se conectan de manera electiva. 
y finalmente los abandonan. Esto es tan claro, que el propio SANDeL reconoce que el yo sólo está parcialmente constituido por su contexto y sus fines, al sostener que el sujeto puede "participar en la constitución de su identidad" ${ }^{45}$. Así pues, es la previsión liberal de proteger la autonomía frente a la imposición de la comunidad, y no la prioridad de ésta última sobre el individuo, la forma de organización política que ofrece una más adecuada autocomprensión de nuestras sociedades. Si las propias visiones comprehensivas que defienden una conexión no electiva con los fines reconocen que el agente moral sólo está parcialmente constituido por éstos, siempre existe la posibilidad, por gravosa e improbable que sea, de revisar, desapegarse o separarse de ellos y, por lo tanto, se dan las condiciones necesarias para que todas las doctrinas comprehensivas se encuentren en un consenso por superposición que distribuya universalmente a las personas el valor de la autonomía, sin duda, el más preciado de los hiperbienes ${ }^{46}$ liberales.

[Recibido el 31 de marzo y aceptado el 24 de abril de 2009].

${ }^{45}$ Sandel, Michael, El liberalismo y los limites de la justicia, cit. (n. 8), p. 191. También es el caso de MacIntyre, Alasdair, Tras la virtud (traducción de Amelia Valcárcel, Barcelona, Crítica, 1987), p. 271, quien sostiene: "la vida buena para el hombre es la vida dedicada a buscar la vida buena para el hombre, y las virtudes necesarias para la búsqueda son aquellas que nos capacitan para entender más y mejor lo que la vida buena para el hombre es". O, más adelante, cuando escribe (p. 272): "la historia de mi vida está siempre embebida en la de aquellas comunidades de las que derivo mi identidad. He nacido con un pasado, e intentar desgajarme de ese pasado a la manera individualista es deformar mis relaciones presentes. La posesión de una identidad histórica y la posesión de una identidad social coinciden. Tengamos presente que la rebelión contra mi identidad es siempre un modo posible de expresarla”. Pero si la vida se entiende de este modo, no parece que se aleje mucho de la insistencia liberal de que la sociedad buena es aquella que deja a las personas descubrir autónomamente lo que es una vida buena [Kukathas, Chandran - Pettit, Philip, La teoría de la justicia de John Rawls (traducción y epílogo de Miguel Ángel Rodilla, Madrid, Tecnos, 2004), p. 119].

${ }^{46}$ Utilizo aquí la nomenclatura de Taylor. Para este filósofo, los hiperbienes son aquellos que no sólo son incomparablemente más importantes que cualquier otro bien, sino que nos proporcionan el punto de vista desde el cual se habrán de balancear y calificar todos los bienes. Véase: TAYLOR, Charles, Fuentes del yo. La construcción de la identidad moderna (traducción de Ana Lizón y revisión técnica de Ramón Alfonso Díez, Barcelona, Paidós, 1996), p. 80. 


\section{BIBLIOGRAFÍA}

Burley, Justine (editora), Dworkin and his Critics (Blackwell Publishing, 2004), $440 \mathrm{pp}$.

Dworkin, Ronald, Ética privada e igualitarismo politico (traducción de Antoni DoMÉNECH, Barcelona, Paidós, 1993), 200 pp.

Dworkin, Ronald, La comunidad liberal (traducción de Claudia Montilla, Santafé de Bogotá, Universidad de los Andes, 1996), 191 pp.

Dworkin, Ronald, Sovereign Virtue. The Theory and Practice of Equality (London, Harvard University Press, 2000), 511 pp.

Kukathas, Chandran - Petтrit, Philip, La teoría de la justicia de John Rawls (traducción y epílogo de Miguel Ángel Rodilla, Madrid, Tecnos, 2004), 248 pp.

Larmore, Charles, Public Reason, en Freeman, Samuel (ed.), The Cambridge Companion to Rawls (New York, Cambridge University Press, 2003), pp. 368-393.

MacIntyre, Alasdair, Tras la virtud (traducción de Amelia Valcárcel, Barcelona, Crítica, 1987), 350 pp.

McCarthy, Thomas, Kantian Constructivism and Reconstructivism: Rawls and Habermas in Dialogue, en Ethics 105 (1994) 1, pp. 44-63.

Mulhall, Stephen - Swift, Adam, El individuo frente a la comunidad. El debate entre liberales y comunitaristas (traducción de Enrique López Castellón, Madrid, Temas de Hoy, 1996), 463 pp.

PeÑa, Carlos, Equilibrio reflexivo, constructivismo y razón pública. El problema de la realidad y la justificación en filosofía política, en Revista de Ciencias Sociales 47 (2002): John Rawls: Estudios en su memoria, pp. 333-437.

Rawls, John, El liberalismo político (traducción de Antoni Domènech, Barcelona, Crítica, 1996), 440 pp.

RAwls, John, Una revisión de la idea de razón pública, en El derecho de gentes (traducción de Hernando Valencia Villa, Barcelona, Paidós, 2001), pp. 155-205.

Rawls, John, La Justicia como equidad. Una reformulación (traducción de Andrés DE Francisco, Barcelona, Paidós, 2002), 287 pp.

Raz, Joseph, The Morality of Freedom (Oxford, Oxford University Press, 1986), 435 pp.

SANDEL, Michael, Liberalism and the Limits of Justice (2a edición, New York, Cambridge University Press, 1998), 249 pp.

SANDel, Michael, El liberalismo y los límites de la justicia (traducción de María Luz Melon, Barcelona, Gedisa, 2000), 238 pp.

Seleme, Hugo, Neutralidad y justicia. En torno al liberalismo politico de John Rawls (Madrid, Marcial Pons, 2004), 362 pp.

TAYLOR, Charles, Fuentes del yo. La construcción de la identidad moderna (traducción de Ana Lizón y revisión técnica de Ramón Alfonso Díez, Barcelona, Paidós, 1996), 609 pp.

Thiebaut, Carlos, Vindicación del ciudadano. Un sujeto reflexivo en una sociedad compleja (Barcelona, Paidós, 1998), 286 pp.

Villavicencio Miranda, Luis, La concepción politica de la persona y las visiones constitutivas del bien, en Ideas y Valores 56 (2007) 135, pp. 29-48.

Wollheim, Richard, A Paradox in the Theory of Democracy, en Laslett Peter - Runciman W. G. (editores), Philosophy, Politics and Society (Oxford, Basil Blackwell, 1967), pp. 71-87. 


